This item was submitted to Loughborough's Research Repository by the author.

Items in Figshare are protected by copyright, with all rights reserved, unless otherwise indicated.

\title{
Identification of plasma protease derived metabolites of glucagon and their formation under typical laboratory sample handling conditions
}

PLEASE CITE THE PUBLISHED VERSION

http://dx.doi.org/10.1002/rcm.7090

PUBLISHER

(c) Wiley

VERSION

AM (Accepted Manuscript)

\section{PUBLISHER STATEMENT}

This work is made available according to the conditions of the Creative Commons Attribution-NonCommercialNoDerivatives 4.0 International (CC BY-NC-ND 4.0) licence. Full details of this licence are available at: https://creativecommons.org/licenses/by-nc-nd/4.0/

\section{LICENCE}

CC BY-NC-ND 4.0

\section{REPOSITORY RECORD}

Howard, James W., Richard G. Kay, Tricia Tan, James Minnion, and Colin S. Creaser. 2019. "Identification of Plasma Protease Derived Metabolites of Glucagon and Their Formation Under Typical Laboratory Sample Handling Conditions". figshare. https://hdl.handle.net/2134/26783. 
$\underline{\text { Identification of plasma protease derived metabolites of glucagon and their formation under }}$ typical laboratory sample handling conditions

James W Howard ${ }^{1,2 \dagger}$, Richard G Kay ${ }^{1}$, Tricia $\operatorname{Tan}^{3}$, James Minnion ${ }^{3}$ and Colin S Creaser ${ }^{2}$

1 LGC, Newmarket Road, Fordham, Cambridgeshire,

CB7 5WW, UK

2 Centre for Analytical Science, Department of Chemistry, Loughborough University, Leicestershire, LE11 3TU, UK

3 Imperial College, Department of Investigative Medicine, Hammersmith Hospital Campus, Du Cane Road, London, W12 0NN, UK

$\dagger$ Author for correspondence. Tel: +44 (0) 1638720 500. Fax: +44 (0)1638 724200

Email: james.howard@1gcgroup.com

SHORT TITLE Identification and characterisation of glucagon metabolites in plasma

KEY WORDS glucagon, peptide metabolism, plasma protease, sample handling, aprotinin stabilisation.

RATIONALE: Glucagon modulates glucose production, and is also a biomarker for several pathologies. It is known to be unstable in human plasma, and consequently stabilisers are often added to samples, although these are not particularly effective. Despite this, there have not been any studies to identify in vitro plasma protease derived metabolites; such a study is described here. Knowledge of metabolism should allow the development of more effective sample stabilisation strategies.

METHODS: Several novel metabolites resulting from the incubation of glucagon in human plasma were identified using high resolution mass spectrometry (MS scan) with positive electrospray ionisation. MS/MS scans were acquired for additional confirmation using a QTRAP. Separation was performed using reversed phase ultra-high performance liquid chromatography. The formation of these metabolites was investigated during a time course experiment and under specific stress conditions representative of typical laboratory handling conditions. Clinical samples were also screened for metabolites. 
RESULTS: Glucagon ${ }_{3-29}$ and $\left[\mathrm{pGlu}^{3}\right.$ glucagon $_{3-29}$ were the major metabolites detected, both of which were also present in clinical samples. We also identified two oxidised forms of $\left[\mathrm{pGlu}^{3}\right.$ glucagon $_{3-29}$ as well as Glucagon $19-29$, or "miniglucagon", along with the novel metabolites glucagon $20-29$ and glucagon $21-29$. The relative levels of these metabolites varied throughout the time course experiment, and under the application of the different sample handling conditions. Aprotinin stabilisation of samples had negligible effect on metabolite formation.

CONCLUSIONS: Novel plasma protease metabolites of glucagon have been confirmed, and their formation characterized over a time course experiment and under typical laboratory handling conditions. These metabolites could be monitored to assess the effectiveness of new sample stabilisation strategies, and further investigations into their formation could suggest specific enzyme inhibitors to use to increase sample stability. In addition the potential of the metabolites to affect immunochemistry based assays as a result of cross-reactivity could be investigated. 


\section{INTRODUCTION}

Glucagon is a 29 amino acid peptide which is one of multiple hormones that modulates glucose production or utilisation to regulate blood glucose levels. It is also a biomarker for pathologies such as diabetes, pancreatic cancer or certain neuroendocrine tumours ${ }^{[1]}$. Endogenous glucagon levels in healthy patients are reported between $25-80 \mathrm{pg} / \mathrm{mL}$, which may be raised by about $10 \mathrm{pg} / \mathrm{mL}$ in pancreatic cancer patients, and can reach up to 160 $\mathrm{pg} / \mathrm{mL}$ in diabetic patients ${ }^{[1]}$.

Glucagon is rapidly metabolised in humans, with a half-life of approx. 5 minutes in healthy subjects, which is raised to approx. 6 minutes in diabetic subjects ${ }^{[2]}$. The liver and kidney are primarily responsible for glucagon metabolism in vivo, although some metabolism also occurs in the blood compartment, and a wide range of metabolites have been identified ${ }^{[3]}$. For example, glucagon ${ }_{4-29}$, glucagon $7-29$, and glucagon ${ }_{1-13}$ are formed by hepatocytes in the liver $^{[4][5]}$. Glucagon $_{1-13}$ and glucagon ${ }_{14-29}$, and the minor metabolites glucagon $1-10$, glucagon $14-$ 25 and glucagon $23-29$, are similarly formed by a glucagon receptor linked protease in the hepatic plasma membrane ${ }^{[3][4]}$. The metabolite known as miniglucagon, glucagon ${ }_{19-29}$, is produced after processing of glucagon by liver plasma membranes ${ }^{[6]}$ and pancreatic cells ${ }^{[7]}$. Miniglucagon has a unique biological activity as a modulator of glucagon ${ }_{1-29}{ }^{[8]}$. Furthermore, in the kidneys, glucagon is hydrolysed at the proximal tubule's brush border in the kidneys ${ }^{[9]}$ by the serine protease dipeptidyl peptidase IV (DPP IV) ${ }^{[10][11]}$. DPP IV is also present in the liver, pancreatic duct, the endothelial cells of the blood vessels, and as a soluble enzyme in blood plasma and therefore similar metabolism is suspected to occur here ${ }^{[11]}$.

Many of these metabolites have the potential for biological activity. For example, although the C-terminal region of glucagon improves receptor binding, peptides lacking this region, such as glucagon ${ }_{1-21}$ and glucagon ${ }_{1-6}$, are essentially fully active glucagon derivatives, but with lower potency ${ }^{[12]}$. In contrast, modifications at the amino-terminus of glucagon, including removal of the His residue, have a greater effect on receptor binding affinity and biological activity ${ }^{[13]}$.

Despite the range of metabolites identified in vivo there have not been any studies to identify in vitro plasma protease derived metabolites. However in serum diluted to $20 \%$ with Tris buffer $(0.1 \mathrm{mM}, \mathrm{pH} 7.6)$, it has been reported that DPP IV hydrolyses glucagon $_{1-29}$ to glucagon $_{3-29}$, which then undergoes immediate conversion to exclusively form pyroglutamyl glucagon $_{3-29}\left([\mathrm{pGlu}]^{3} \text { glucagon }_{3-29}\right)^{[10]}$. This may partially account for the instability glucagon 
shows in human plasma. For samples intended for glucagon quantitation, inhibitors, such as the serine proteinase inhibitor aprotinin or the proprietary P800 cocktail inhibitors are often added to samples to stabilise them. However, the effectiveness of these is controversial, for example it has been shown that glucagon levels are unaffected by the presence of aprotinin [14]. Similarly, whilst some studies demonstrated that P800 cocktails inhibitors increase glucagon half-life to at least 16 hours ${ }^{[15]}$ and 48 hours ${ }^{[16]}$, another demonstrated they had an insignificant effect ${ }^{[17]}$.

In view of the wide range of metabolites formed in vivo it seemed likely that plasma metabolites would also be formed in vitro. The formation of additional metabolites could also help to explain the poor precision and accuracy ${ }^{[18][19][20]}$ experienced by many immunoassay based glucagon quantitation kits due to cross reactivity with them. Cross reactivity with peptides related to glucagon (oxynotomodulin and/or glicentin) has been reported in 4/7 immunoassay kits ${ }^{[19]}$ and in $1 / 3$ sandwich ELISA kits ${ }^{[20]}$ recently evaluated. It could also help to explain the 7-fold difference in endogenous glucagon concentrations reported by immunoassays directed against the middle or C-terminal regions of glucagon ${ }^{[21]}$. LC/MS assays have the potential to circumvent such issues; however until recently ${ }^{[22][23]}$ such assays were not sensitive enough to detect endogenous glucagon ${ }^{[24][25][26]}$.

In this article we report the identification of novel metabolites formed in vitro by human plasma protease metabolism of glucagon, and characterise their formation. We also assess metabolite formation under typical laboratory sample handling conditions, and investigate the effectiveness of aprotinin stabilisation. 


\section{EXPERIMENTAL}

\section{Materials}

Certified human glucagon (HSQGTFTSDYSKYLDSRRAQDFVQWLMNT) was obtained from EDQM (Strasbourg, France). Water was produced by a Triple Red water purifier (Buckinghamshire, U.K.). Human plasma was obtained from CTLS (London, UK). Aprotinin from BioUltra was obtained from Sigma-Aldrich (Dorset, UK). Plasma was stabilised using aprotinin at $100 \mathrm{KIU} / \mathrm{mL}$ as appropriate. All chemicals and solvents were HPLC or analytical reagent grade and purchased from commercial vendors.

\section{Preparation of Glucagon Stock Solutions}

$1 \mathrm{mg} / \mathrm{mL}$ glucagon stock solutions were prepared in borosilicate vials using $\mathrm{MeOH}: \mathrm{H}_{2} \mathrm{O}$ : formic acid (FA): bovine serum albumin (BSA), (20:80:0.1:0.1, v/v/v/w) as a solvent and stored at $-20^{\circ} \mathrm{C}$ when not in use.

\section{Preparation of Metabolite Samples}

Glucagon samples were prepared by diluting the stock solution 100 fold with human plasma to create samples at $10 \mu \mathrm{g} / \mathrm{mL}$. Plasma was unstabilised unless stated otherwise. Samples were extracted either immediately, or after storage at set time points under specific conditions. Samples were extracted on wet ice $\left(\mathrm{ca}+4{ }^{\circ} \mathrm{C}\right)$ using a protein precipitation methodology. Briefly samples $(100 \mu \mathrm{L})$ were placed into a $1 \mathrm{~mL} 96$ well plate polypropylene plate, precipitated using $500 \mu \mathrm{L}$ of acetonitrile $(\mathrm{ACN}): \mathrm{H}_{2} \mathrm{O}$ (75:25), vortex mixed, and then centrifuged for 10 minutes at $2300 \mathrm{~g}$. The supernatant was transferred to a $1 \mathrm{~mL} 96$ well lobind plate and evaporated to dryness under nitrogen at $40{ }^{\circ} \mathrm{C}$. Samples were reconstituted in $700 \mu \mathrm{L} 0.2 \%$ formic acid (aq) to form "concentrated extracts", vortex mixed and centrifuged again, before being analysed by LC/MS as described below. To avoid the most abundant metabolites leading to detector saturation the extracts were also diluted to form "diluted extracts" and re-analysed by LC/MS. For this dilution, $100 \mu \mathrm{L}$ of the "concentrated extracts" was added to $250 \mu \mathrm{L} 0.2 \%$ formic acid (aq) and $350 \mu \mathrm{L}$ MeOH: $\mathrm{H}_{2} \mathrm{O}$ : FA: BSA, (20:80:0.1:0.1, v/v/v/w) in a $1 \mathrm{~mL} 96$ well lo-bind plate, before being vortex mixed and centrifuged.

\section{Initial Metabolite ID Experiments}

The LC/MS system consisted of a Waters Acquity UPLC system (Waters Corporation, Milford, Massachusetts, USA) coupled to an AB SCIEX 5500 QTRAP (Applied Biosystems 
/ MDS SCIEX, Ontario, Canada) with an electrospray ion source. Data acquisition and processing were performed using Analyst 1.5.2 (Applied Biosystems/ MDS SCIEX).

The mass spectrometer was operated in positive ion mode with an electrospray voltage of $5500 \mathrm{~V}$, an entrance potential of $10 \mathrm{~V}$, and a declustering potential of $70 \mathrm{~V}$. The source temperature was $600{ }^{\circ} \mathrm{C}$, the nitrogen curtain gas $40 \mathrm{Psi}$, and the nitrogen desolvation gases, GS1 and GS2, were set at 60 psi and 40 psi respectively. Full scan spectra were acquired using quadruple mode over the range $\mathrm{m} / \mathrm{z} 450$ - 1250 with a scan rate of $2000(\mathrm{~m} / \mathrm{z}) / \mathrm{sec}$ and with unit resolution.

Glucagon was separated on a Waters UPLC BEH C18 $1.7 \mu \mathrm{m}(2.1$ x $100 \mathrm{~mm})$ column maintained at $60{ }^{\circ} \mathrm{C}$. The mobile phase consisted of (A) $0.2 \% \mathrm{FA}(\mathrm{ACN})$ and (B) $0.2 \% \mathrm{FA}$ (aq). The gradient for separation was $10-50 \%$ A over 7.9 minutes. The column was then cleaned with $95 \%$ A for approx. 1 minute then 10\% A for approx. 4 minutes. The flow rate was $0.8 \mathrm{~mL} / \mathrm{min}$ and the total run time 13 minutes. $10 \mu \mathrm{L}$ of the "concentrated extracts" from plasma samples incubated at 0 hours and 25 hours at room temperature was injected, and the total ion chromatograms were compared to putatively identify metabolites.

An Enhanced resolution (ER) spectrum of the 25 hour sample was similarly acquired using linear ion trap mode with a scan rate of $250(\mathrm{~m} / \mathrm{z}) / \mathrm{sec}$ over the mass range $\mathrm{m} / z, 800-830$. An Enhanced Product Ion (EPI) spectrum of the $\mathrm{m} / z 815.6$ ion from the 25 hour sample was also similarly acquired using Q1 at unit resolution to select the precursor, and using the linear ion trap at a scan rate of $10,000(\mathrm{~m} / \mathrm{z}) / \mathrm{sec}$ over the range $\mathrm{m} / \mathrm{z} 100-1000$ to monitor the product ions.

\section{Metabolite ID Confirmation}

The LC/MS system consisted of a Dionex LC system (Thermo Scientific, Waltham California, USA) coupled to Q Exactive Orbitrap system (Thermo Scientific) with an electrospray ion source operating in positive ion mode. A scan range of $m / z 233.4-3500$ was selected with a resolution of 140,000 (FWHM) with centroid data acquisition. Data acquisition and processing were performed using Xcalibur V2.2 (Thermo Scientific). The LC conditions were based on those described above. A "concentrated extract" of a sample incubated for 75 hours at room temperature was injected $(10 \mu \mathrm{L})$, and peaks corresponding to those observed during the analysis with the AB SCIEX 5500 Q TRAP were observed. 


\section{Time Course Studies}

Samples were prepared and extracted as described above after 0, 0.5, 1.5, 3, 25, 49, and 75 hours storage at room temperature. Quantitation was performed using the LC/MS system used for the initial metabolite ID experiments, but using selected reaction monitoring (SRM) transitions; $m / z \quad 697.5 \rightarrow 693.8, \mathrm{~m} / \mathrm{z} \quad 815.6 \rightarrow 811.0, \mathrm{~m} / \mathrm{z} 676.9 \rightarrow 478.2, \mathrm{~m} / \mathrm{z} \quad 641.3 \rightarrow 632.3, \mathrm{~m} / \mathrm{z}$ $577.3 \rightarrow 478.2$, and $m / z 811.1 \rightarrow 807.0$. These transitions corresponded to the most sensitive SRM transitions for Glucagon $1-29$, Glucagon ${ }_{3-29}$, Glucagon ${ }_{19-29}$, Glucagon $_{20-29}$, Glucagon $_{21-29}$, and $\left[\mathrm{pGlu}^{3}\right.$ glucagon $_{3-29}$ respectively. The nitrogen collision gas was set to medium and both transitions used collision energies of $15-20 \mathrm{eV}$ and collision exit well potentials of $13 \mathrm{eV}$.

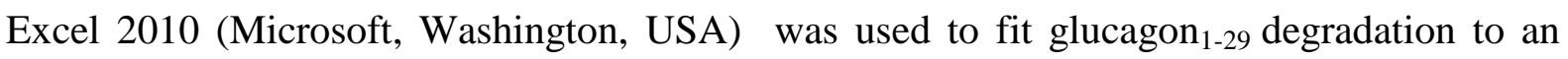
exponential equation.

\section{Metabolite Formation in Solution}

Glucagon stock solutions $(1 \mathrm{mg} / \mathrm{mL})$ were stored at $-20{ }^{\circ} \mathrm{C}$ for 310 days or under ambient conditions for 50 hours, and diluted to $204 \mathrm{ng} / \mathrm{mL}$ with $\mathrm{MeOH}: \mathrm{H}_{2} \mathrm{O}$ : FA: BSA, (20:80:0.1:0.1, v/v/v/w) prior to analysis with the SRM method described above.

\section{Metabolite Formation in Unstablised and Aprotinin Stabilised (100 KIU/mL) Human Plasma}

Aprotinin stabilised $(100 \mathrm{KIU} / \mathrm{mL})$ or unstabilised human plasma glucagon samples were prepared to a concentration of $10 \mu \mathrm{g} / \mathrm{mL}$ as described above. Samples were extracted as described above after; storage for 0 hour, at room temperature or $4{ }^{\circ} \mathrm{C}$ for 6 hours 20 minutes and 26 hours, after 4 freeze-thaw cycles $\left(-20^{\circ} \mathrm{C}\right.$ to $\left.4{ }^{\circ} \mathrm{C}\right)$ and $\left(-80^{\circ} \mathrm{C}\right.$ to $\left.+4{ }^{\circ} \mathrm{C}\right)$, and after 1 month and 5 months storage at $-20{ }^{\circ} \mathrm{C}$ or $-80{ }^{\circ} \mathrm{C}$. In all cases $\mathrm{n}=6$ replicates were extracted. "Concentrated extracts" and "diluted extracts" were analysed using the SRM method described above.

\section{Metabolites formed in Physiological Study Samples}

Physiological Study Samples were obtained from Imperial College London. The samples originated from 5 different individuals who were each infused with a glucagon solution at either 16 or $20 \mathrm{pmol} / \mathrm{kg} / \mathrm{min}$ for 12 hours subcutaneously. Blood samples at various time points were collected in $5 \mathrm{~mL}$ lithium heparin collection tubes containing $1000 \mathrm{KIU}$ of Aprotinin, spun down in a cold centrifuge within 5 to 10 mins of collection, and then stored at $-20{ }^{\circ} \mathrm{C}$. The samples $(\mathrm{n}=87)$ were analysed using the $2 \mathrm{D}$ extraction procedure described 
previously [23], and the SRM method described above. The study was approved by the West London Research Ethics Committee (reference no.11/LO/1782). All volunteers gave written informed consent, and the study was planned and performed in accordance with the Declaration of Helsinki ${ }^{[27]}$. 


\section{RESULTS AND DISCUSSION}

\section{Initial Metabolite ID Experiments (LRMS)}

Initial metabolite ID experiments were performed using low resolution mass spectrometry (LRMS) in full scan mode $(\mathrm{m} / \mathrm{z}$ 450-1250). Overlaying spectra from spiked glucagon human samples stored at room temperature for 0 hours and 25 hours revealed several potential metabolite peaks (Figure 1).

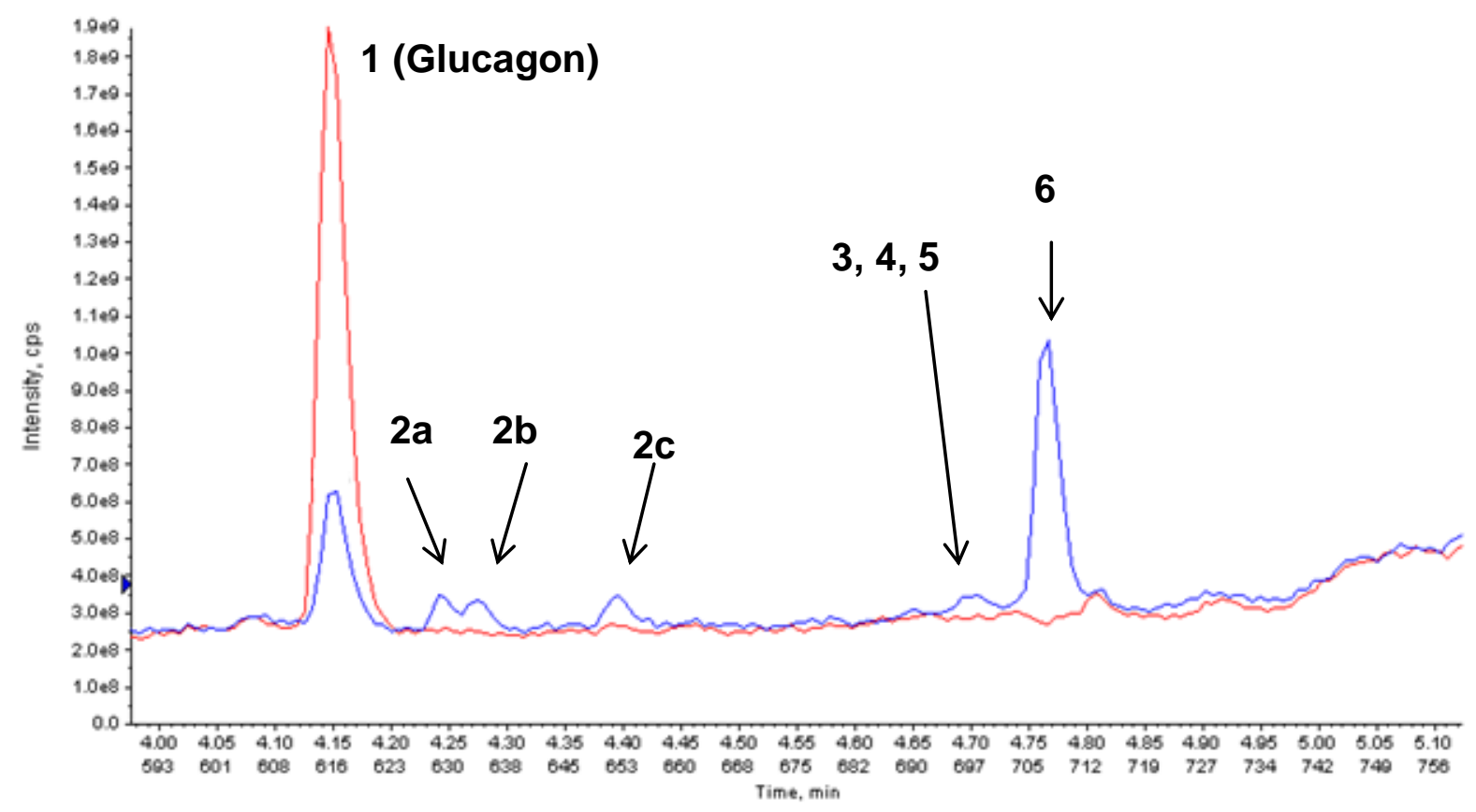

\section{Figure 1 Overlay of MS full scan total ion chromatograms (TICs) from spiked} glucagon samples $(10 \mu \mathrm{g} / \mathrm{mL})$ stored at room temperature for 0 hours (red) and 25 hours (blue).

The mass spectrum from peak 1 contained ions corresponding to the parent glucagon $_{1-29}$ molecule, whilst peak 6 contained ions corresponding to the $3+$ and $4+$ charge state of the known $20 \%$ serum (buffer) metabolite $[\mathrm{pGlu}]^{3}$ glucagon $_{3-29}$. The peak at approximately 4.7 minutes was found to have several ions with $\mathrm{m} / \mathrm{z}$ values consistent with glucagon ${ }_{19-29}$, glucagon $_{20-29}$, and glucagon $21-29$. It was determined that these three metabolites eluted at slightly different retention times (Peaks 3, 4, and 5 respectively). 
Peaks 2a, 2b and 2c, contained similar ions that corresponded approximately to those expected by the $3+$ and $4+$ charge state of glucagon ${ }_{3-29}$ (Table 1). Glucagon $3-29$ was not reported in the related matrix $20 \%$ serum (buffer), as it was suggested that the cyclisation to form $[\mathrm{pGlu}]^{3}$ glucagon $3-29$, occurred immediately (Figure 2) ${ }^{[10]}$.Such cyclisation may be performed by a transglutaminase serum enzyme such as glutaminyl cyclase. ${ }^{[28]}$ It is possible that such enzymes are less active in plasma than in buffered serum, thereby allowing significant levels of glucagon $3-29$ to remain. The enzymatic nature of the cyclisation may also explain why it does not occur for position 2 modified glucagon analogs ${ }^{[13]}$, as these may introduce steric hindrance.

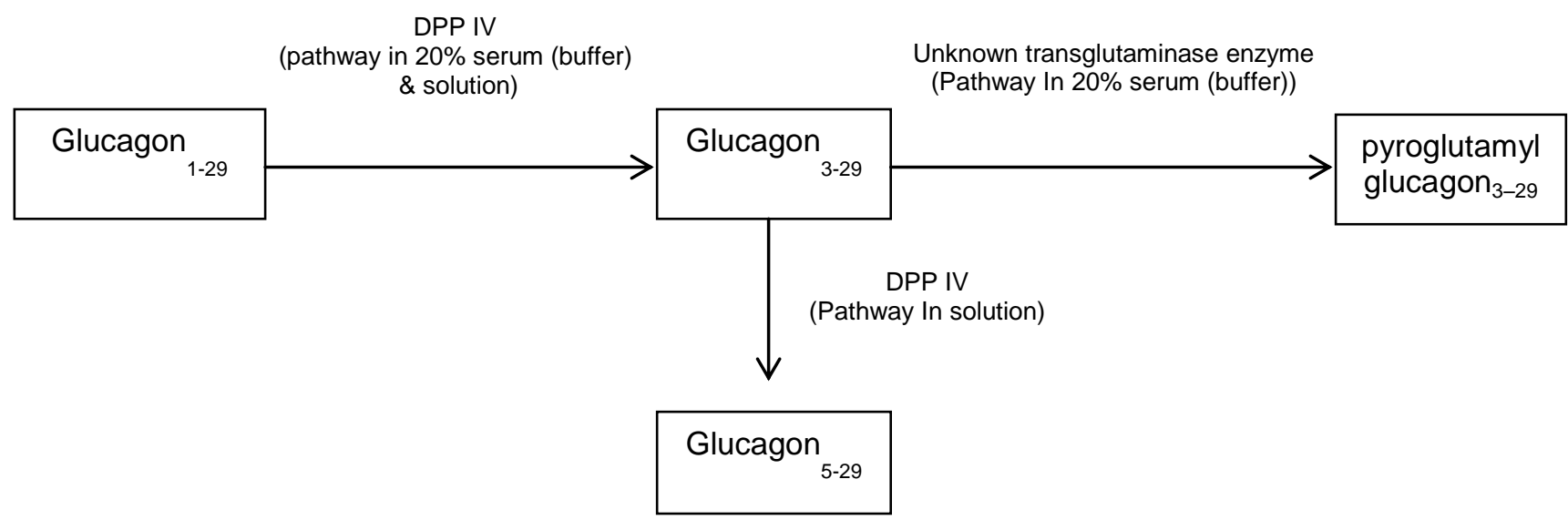

Figure 2 Metabolism of glucagon by dipeptidyl peptidase IV (DPP IV) in solution and in $20 \%$ human serum (buffer) reported in the literature ${ }^{[10]}$.

Previously double peaks were observed for glucagon ${ }_{3-29}$ in solution, which were attributed to cis/trans isoforms of the truncated molecules ${ }^{[10]}$. To investigate whether this could be the origin of the multiple peaks observed in human plasma, a higher resolution scan was acquired using the ion trap functionality of the mass spectrometer (Figure 3). The first isotopic peak detected in 2a was $m / z$ 814.8, whilst in 2c it was $m / z$ 815.1. Taking into account the 4+ charge state, this corresponds to approximately one mass unit difference, demonstrating that the species are not isoforms. The spectrum for $2 \mathrm{~b}$ was not of a high enough quality for a similar comparison to be made. Often when a peptide is one mass unit higher than expected it is indicative that a deamidation has occurred, however this is not thought to be the case here as the deamidated product usually elutes earlier than the native form. 
The MS/MS spectra suggested that $2 \mathrm{a}$ and $2 \mathrm{~b}$ were similar, but that $2 \mathrm{c}$ was markedly different showing less overall fragmentation as evidenced by the high intensity of the precursor ion (Figure 3). Assuming neutral loses (i.e. no loss of charge), metabolites $2 \mathrm{a}$ and $2 \mathrm{~b}$ show losses of approximately $17.6 \mathrm{Da}$, which may correspond to water. Whereas $2 \mathrm{c}$ shows losses of approximately 17.2 Da and 17.6 Da, which may correspond ammonia and water respectively. Despite this putative structural information, it was not possible to confirm the identity of metabolites $2 \mathrm{a}, 2 \mathrm{~b}$ or $2 \mathrm{c}$ at the resolution offered by LRMS.

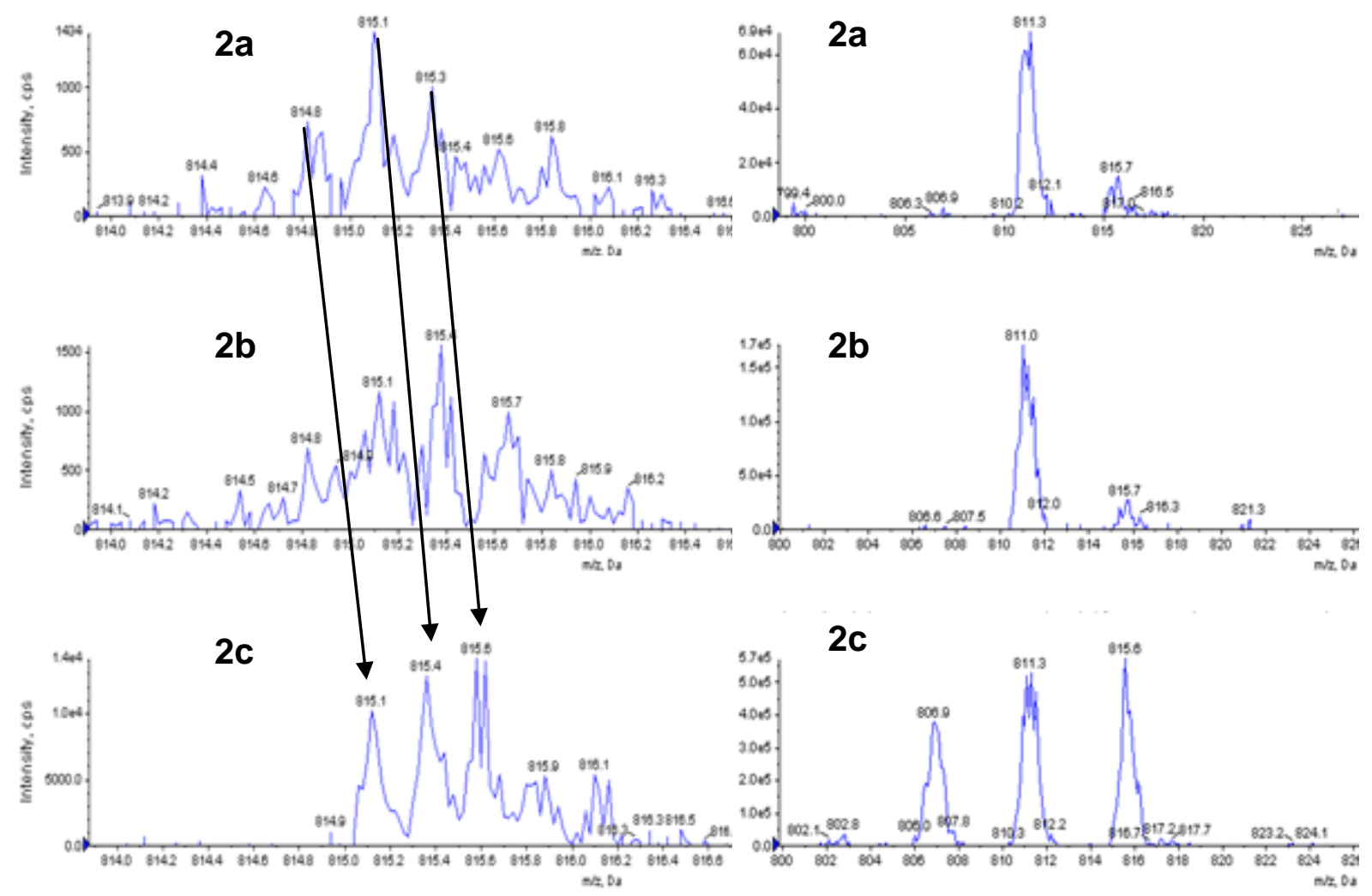

Figure 3 Left- Higher resolution MS data of a spiked glucagon sample $(10 \mu \mathrm{g} / \mathrm{mL})$ stored at room temperature for 25 hours.

Right- Product ion (MS/MS) data of $m / z, 815.6$ from a spiked glucagon sample $(10 \mu \mathrm{g} / \mathrm{mL})$ stored at room temperature for 25 hours.

In summary, LRMS allowed 8 metabolites to be detected and putatively identified (Table 1) However due to the low mass accuracy of the technique it was not possible to distinguish between the metabolites corresponding to peaks $2 \mathrm{a}, 2 \mathrm{~b}$, and $2 \mathrm{c}$; all of which were assigned the putative identity of glucagon ${ }_{3-29}$. Therefore further studies were performed using high resolution mass spectrometry (HRMS). 


\section{Metabolite ID Confirmation (HRMS)}

High resolution mass spectrometry (HRMS) at a resolving power (FWHM) of 140,000 at $\mathrm{m} / \mathrm{z}$ 200 , led to a resolution of $m / z 0.001^{[29]}$, as exemplified in Figure 4. This allows $<5$ ppm mass accuracies to be achieved, rather than the several hundred ppm offered by the LRMS, and therefore provided sufficient mass accuracy for the unequivocally identification of novel species. In addition, the HRMS instrument has a higher $m / z$ limit than the LRMS spectrometer $(\mathrm{m} / \mathrm{z} 4000, \mathrm{cf} 1250)$ allowing a greater number of charge states to be observed for additional confirmation.

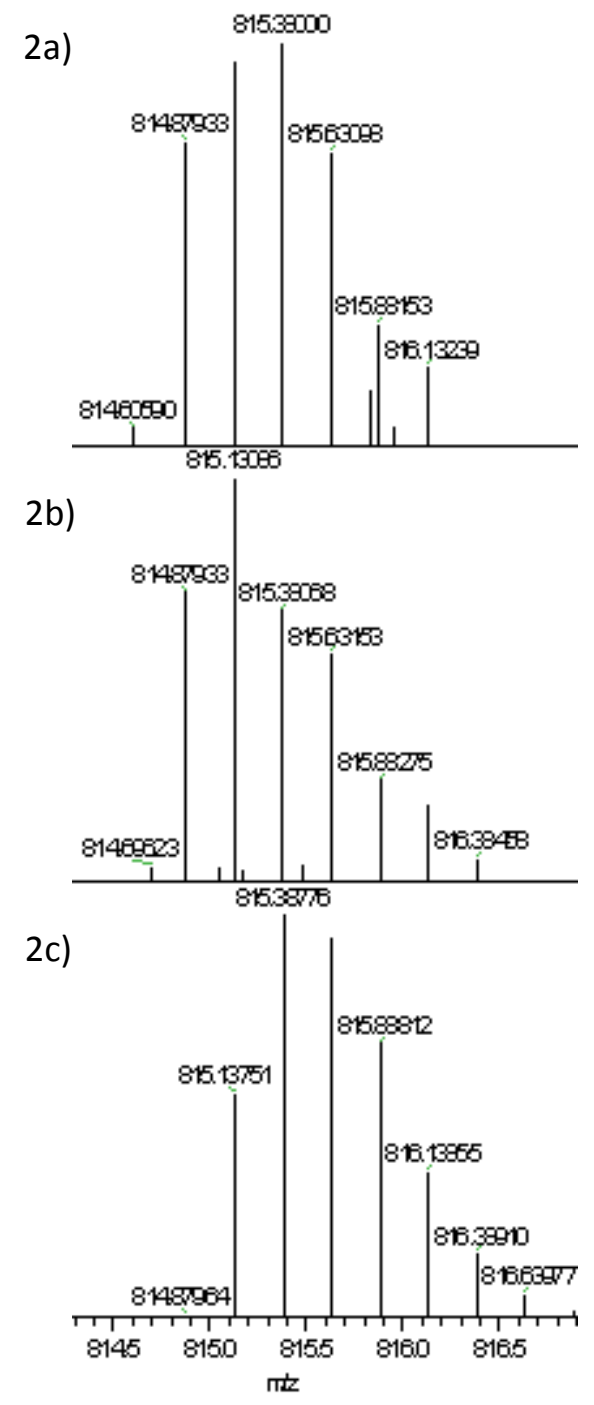

Figure 4 HRMS data observed for peaks 2a (top), $2 b$ (middle), and 2c (bottom). Much higher resolution is obtained than with the QTRAP operating in linear ion trap mode (Figure 3). 
A spiked glucagon sample $(10 \mu \mathrm{g} / \mathrm{mL})$ stored at room temperature for 75 hours was analysed using HRMS. Peaks corresponding to those observed during the analysis with the Q TRAP were identified and metabolite IDs determined (Table 2). Peak 4 was confirmed as $[\mathrm{pGlu}]^{3}$ glucagon $_{3-29}(\leq \pm 2.0 \mathrm{ppm})$ and Peak 2c was assigned as glucagon ${ }_{3-29}(\leq \pm 2.0 \mathrm{ppm})$. Peaks $2 \mathrm{a}$ and $2 \mathrm{~b}$ were assigned as oxidised [pGlu] $]^{3}$ glucagon $_{3-29}(\leq \pm 2.0 \mathrm{ppm})$. The assignments of peaks $2 \mathrm{a}, 2 \mathrm{~b}$ and $2 \mathrm{c}$ are corroborated by the MS/MS data acquired by LRMS (Figure 3), as only glucagon $3-29$ can produce a product ion corresponding to the loss of the terminal ammonia, as this has already occurred from the oxidised [pGlu] ${ }^{3}$ glucagon $_{3-29}$ forms due to pyroglutamisation.

The oxidised forms of $\left[\mathrm{pGlu}^{3}\right.$ glucagon $_{3-29}$ are likely to be two diastereomeric methionine sulfoxide (MetO) peptides formed by methionine oxidation (Figure 5). $\mathrm{Met}(\mathrm{O})$ peptides are the only stable peptide oxidation products, unlike for example reversible cysteine sulfenic acid formation, which only act as transient intermediates ${ }^{[30]}$. The $\mathrm{S}$ and $\mathrm{R}$ forms of $\operatorname{Met}(\mathrm{O})$ peptides can be however be reduced back to Met by methionine sulfloxide reductases (Msrs) A (msrA) and B (msrB) respectively, in roles associated with protection of peptides against oxidative stress and regulation of the aging process ${ }^{[31]}$.

It is not possible to assign each peak to a particular methionine sulfoxide diastereoisomer, as no robust method exists ${ }^{[32]}$. The partially resolved nature of peaks $2 \mathrm{a}$ and $2 \mathrm{~b}$ corroborates their assignment, as peptides containing diastereomers of $\operatorname{Met}(\mathrm{O})$ are known to be challenging to separate under reversed-phase liquid chromatography conditions ${ }^{[32]}$.

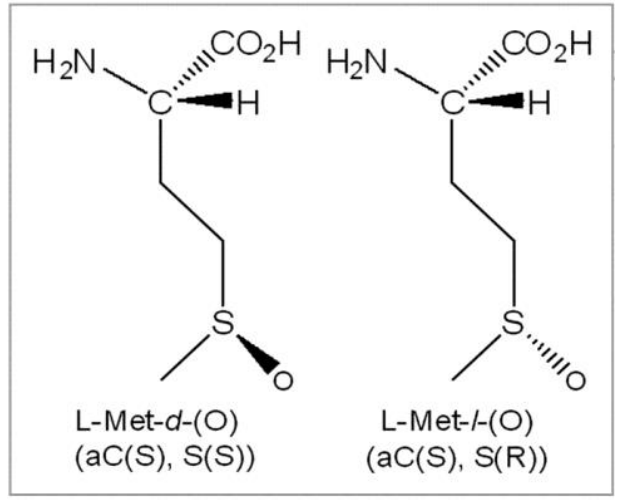

Figure 5 Diastereomeric structure of methionine sulfoxide, Met-S-(O) and Met-R$(O)$. Here, Met-S-(O) denotes the diastereomer with the $(S)$ configuration at the alpha carbon and (S) configuration at the sulfur, whereas Met-R$(O)$ indicates the $(S)$ configuration at the alpha carbon and $(R)$ configuration at the sulphur ${ }^{[32]}$. 
Peaks 3, 4, and 5 were confirmed as glucagon $21-29$, glucagon $_{20-29}$, and glucagon ${ }_{19-29}$ to within $\leq \pm 3.8 \mathrm{ppm}$. These peaks showed lower mass accuracies than the other metabolites, which is likely to be due to their lower abundances limiting mass spectrometer signal. Glucagon $_{19-29}$, or miniglucagon, has previously only been identified in liver plasma membranes ${ }^{[6]}$ and pancreatic cells ${ }^{[7]}$, whereas glucagon $20-29$, and glucagon $21-29$ have not been previously reported. Miniglucagon, has its own unique biological activity, which is opposite to that of gluagon ${ }_{1-29}$, and thus acts as a modulator ${ }^{[8]}$. Further studies are needed to determine whether glucagon $20-29$ and glucagon $21-29$ might have similar roles. It has been suggested that glucagon $_{19-29}$, is formed by insulin degrading enzyme (IDE), a neutral thiolmetalloendopeptidase, also called insulysin, in liver cells by the cleavage of $\mathrm{Arg}^{18}-\mathrm{Ala}^{19}$ bonds ${ }^{[33]}$. However other studies have suggested that IDE cleaves at $\operatorname{Arg}^{17}-\mathrm{Arg}^{18}$ bonds with the formation of glucagon ${ }_{18-29}$, which may then be converted into glucagon ${ }_{19-29}$ by an unidentified aminopeptidase like enzyme ${ }^{[34]}$. It is possible that such residual hepatocyte enzymes are present in plasma leading to the formation of glucagon ${ }_{19-29}$, and perhaps lead to the formation of glucagon $20-29$ and glucagon ${ }_{21-29}$ by similar unidentified aminopeptidase like enzymes. 


\section{Time Course Studies}

Incubation of glucagon in human plasma at room temperature for various times $(0,0.5,1.5,3$, 25,49 , and 75 hours) showed the rate of glucagon degradation and metabolite formation (Figure 6). Due to the differences in abundances of the species it was not possible to accurately analyse all species in the same run, as an extract concentration that ensured sufficient signal for lower abundant species led to saturation for higher abundant species. Therefore the extracts were analysed twice; once "concentrated" and once "diluted".
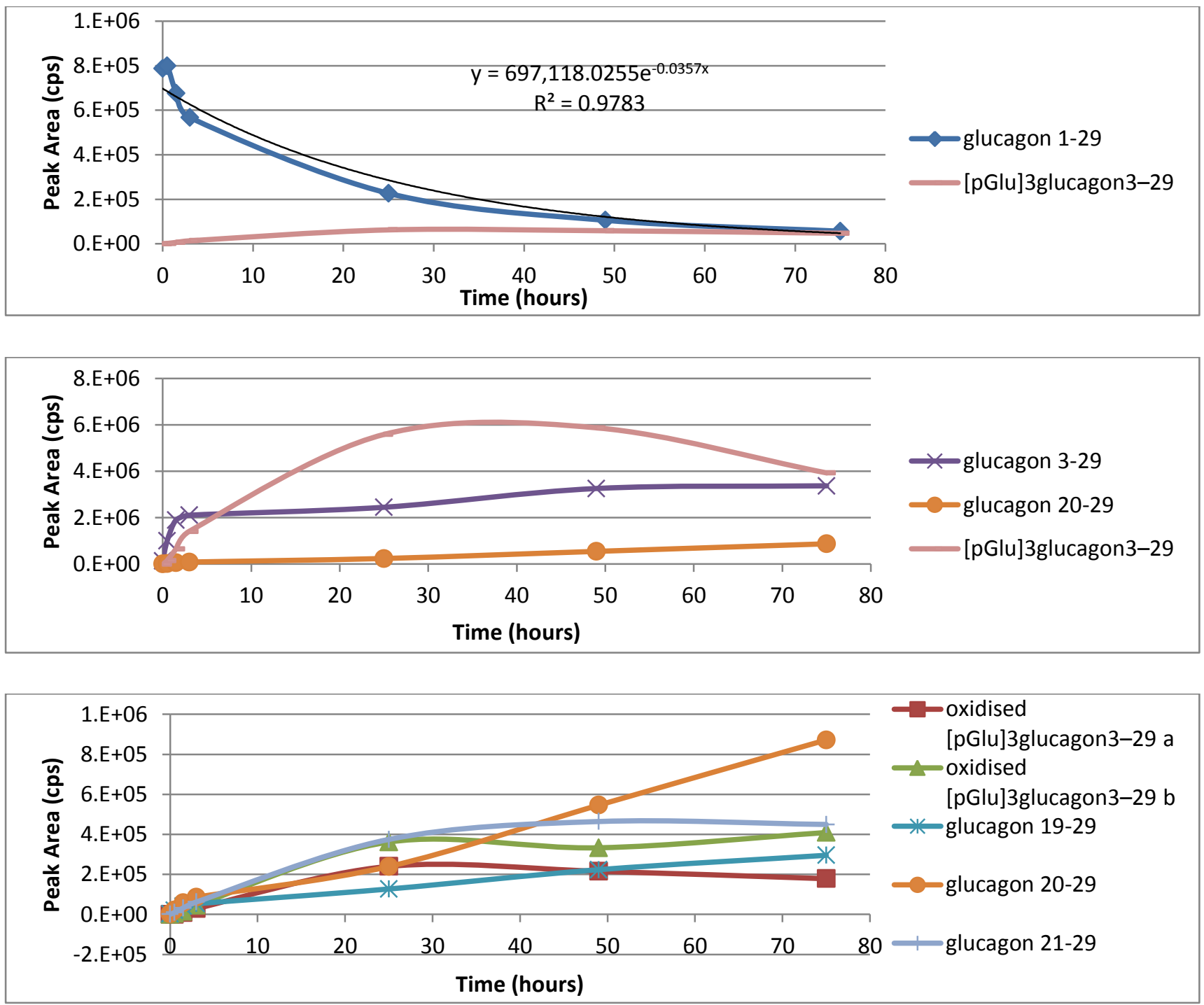

Figure 6 Degradation of glucagon, and formation of metabolites, by human plasma incubated at room temperature, monitored by SRM mass spectrometry. Top (injection of the "diluted extract"); Middle+ Bottom (injection of the "concentrated extract"). 
LC/MS peak areas were used to create the metabolite profiles. Whilst these are not expected to be absolutely related to molar metabolite abundances, due to differences in ionisation ability of the metabolites, there is expected to be a loose correlation.

Glucagon $_{1-29}$ decayed with an observed half-life $\left(\mathrm{t}_{1 / 2}\right)$ of 12.5 hours. This is considerably less than the calculated $\left(\mathrm{t}_{1 / 2}\right)$ of 19.2 hours from the fitted exponential curve, demonstrating the decay is only approximately exponential. Glucagon ${ }_{3-29}$ was the metabolite that gave the most intense signal between $0.5-3$ hours, whilst the previously reported $20 \%$ serum (buffer) metabolite $[\mathrm{pGlu}]^{3}$ glucagon ${ }_{3-29}$ was the most intense at later time points. This was expected due to the reported irreversible cyclisation of the $\mathrm{N}$ terminal of glucagon $_{3-29}$ to form pyroglutamyl ${ }^{[10]}$.

$\left[\mathrm{pGlu}^{3}{ }^{\text {glucagon }}{ }_{3-29}\right.$ signal peaks at approximately 32 hours before decreasing, indicating that it is itself metabolised. Oxidised metabolites are first detected at 1.5 hours, compared to 0.5 hours for the [pGlu] $]^{3}$ glucagon ${ }_{3-29}$ metabolite. The oxidised $a$ and $b$ forms show similar profiles and peak at approximately 30 hours, a similar time to the parent metabolite. However the $b$ forms starts to increases again at 75 hours, whereas the $a$ form continues to decrease. In addition, the $a$ form gives a lower signal than the $b$ form. Whilst the oxidation of the free amino acid Met by hydrogen peroxide in aqueous solution yields a racemic diastereomeric mixture of methionine sulfoxides ${ }^{[35]}$, this will not necessary be the case when Met is part of a larger peptide and undergoing enzymatic oxidation. Therefore it is not unexpected that different signals were measured, or that the profiles for the two oxidised metabolites are slightly different.

The novel metabolite Glucagon $21-29$ initially had the fastest rate of formation of the minor metabolites, however this slowed with time and abundance peaked at approximately 49 hours before decreasing. In contrast Glucagon ${ }_{19-29}$, or miniglucagon, and the novel metabolite Glucagon $20-29$ showed relatively linear rates of formation, and abundance of these metabolites does not appear to have peaked. It might be expected that these small peptides are formed sequentially, however the kinetics plots do not corroborate a simple model for this, as the larger peptides (glucagon $_{19-29}$ and glucagon $20-29$ ) continue to increase in abundance with time, whereas the smallest peptide (glucagon $21-29$ ) plateaus and starts to decrease. Longer time course studies may allow the metabolism of these small peptides to be better understood, but for a more complete understanding synthetic peptides of these metabolites could be acquired and incubated. 
The degradation of glucagon and the formation of metabolites in human plasma samples subjected to typical laboratory handling conditions

No metabolites were observed when glucagon solutions at $1 \mathrm{mg} / \mathrm{mL}$ were stored at $-20{ }^{\circ} \mathrm{C}$ for 310 days or under ambient conditions for 50 hours. Hence confirming that the metabolites do not arise from impurities in the reference material nor are they formed in solution under normal experimental conditions.

In order to access the formation of metabolites under typical laboratory handling conditions, samples were prepared in unstabilised human plasma at $10 \mu \mathrm{g} / \mathrm{mL}$. Due to the controversy over the ability of Aprotinin to prevent glucagon degradation ${ }^{[14]}$. Further samples were also prepared in plasma containing $100 \mathrm{KIU} / \mathrm{ML}$ of Aprotinin to investigate this. Figure 7 and Figure 8 shows metabolite formation under the applied conditions.

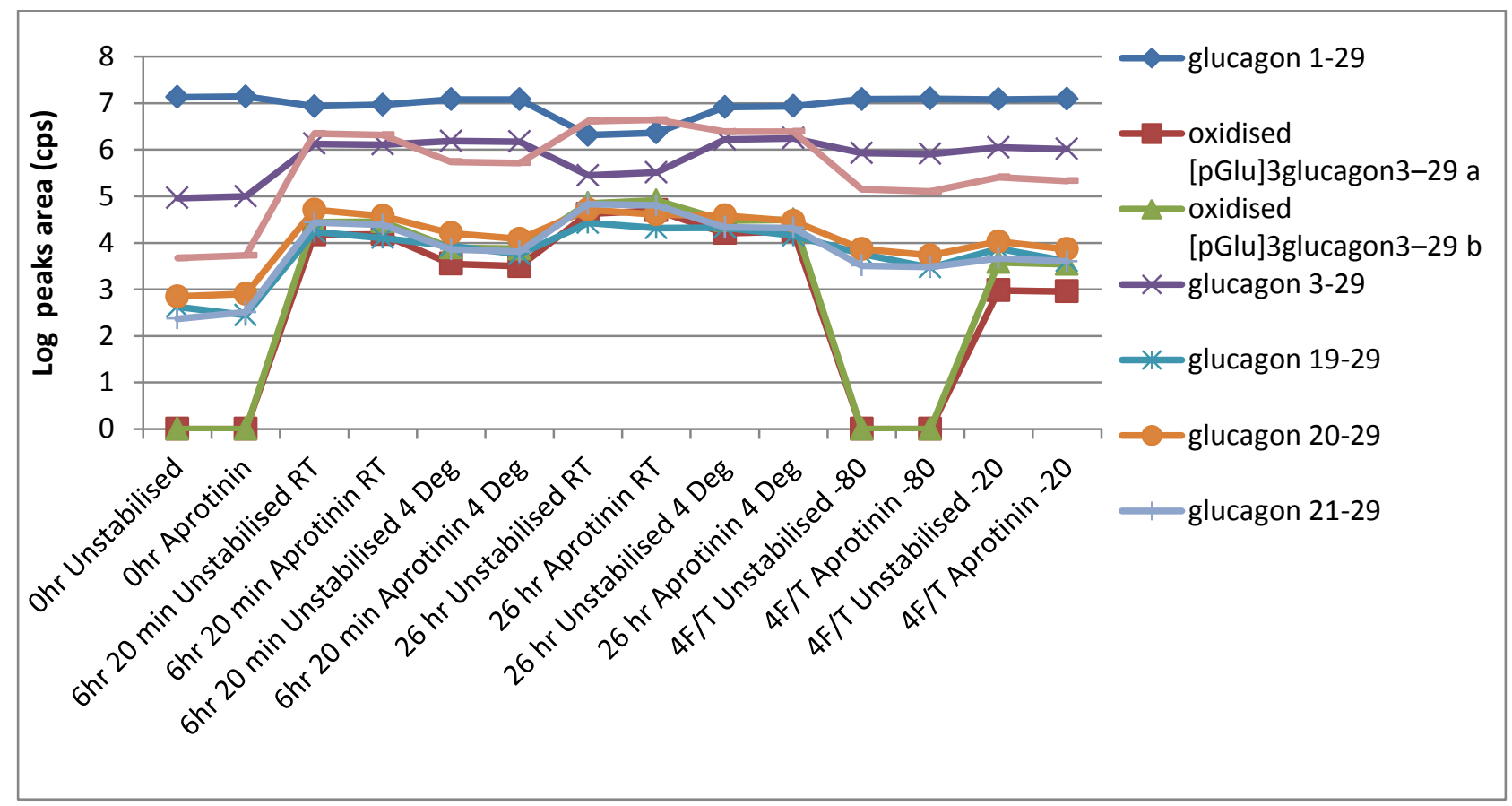

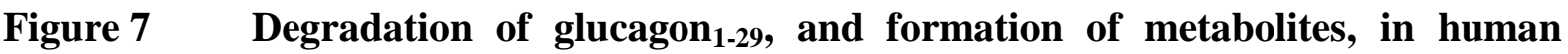
plasma samples placed under various conditions monitored by SRM mass spectrometry. This figure and Figure 8 are created from data acquired by injecting the "concentrated extract" and consequently underestimate

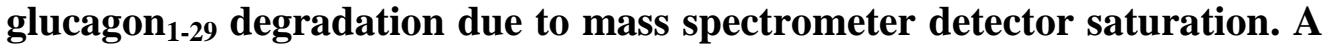
"diluted extract" was injected to assess glucagon ${ }_{1-29}$ degradation, and provides the glucagon degradation values quoted in the text. 


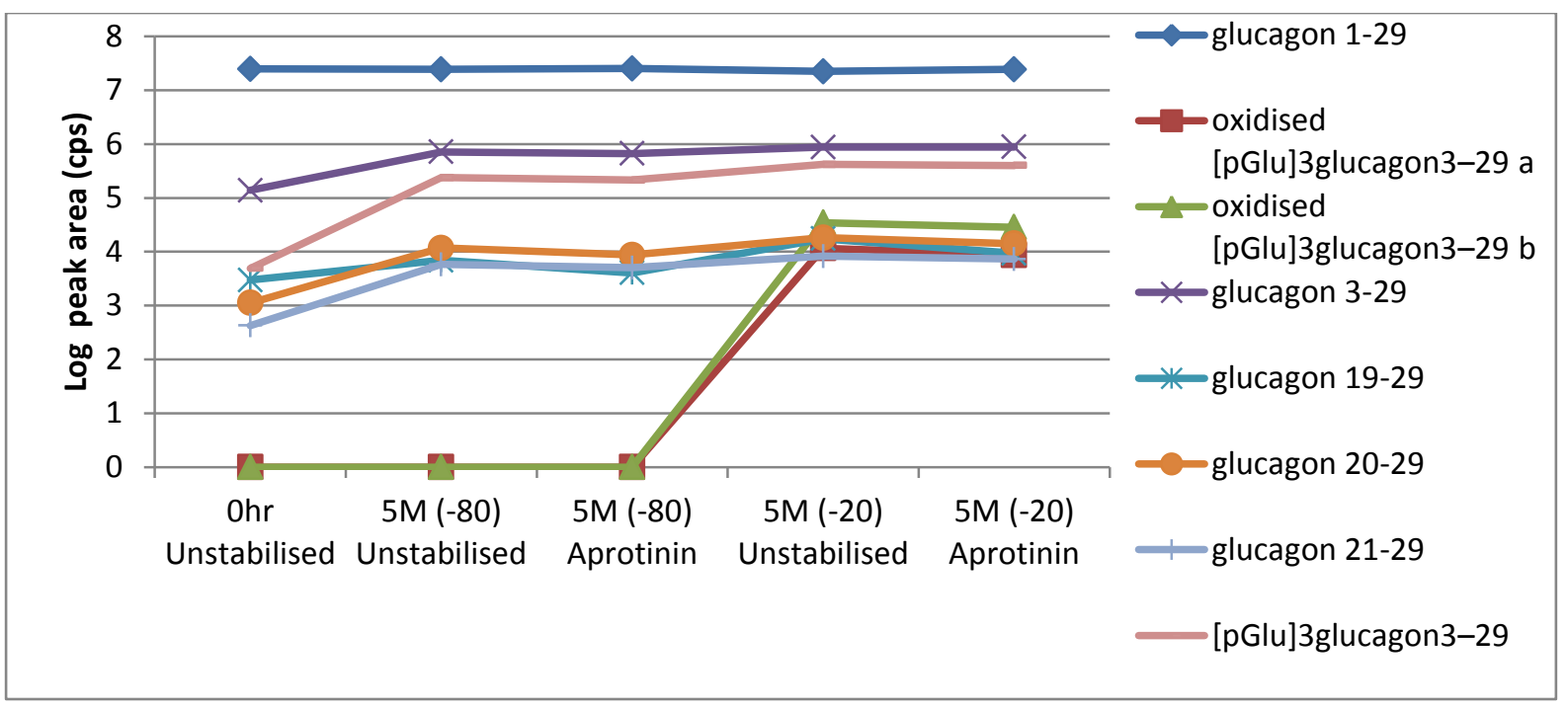

Figure 8 Degradation of glucagon ${ }_{1-29}$ and formation of metabolites, in human plasma samples placed following storage in a freezer at $-20{ }^{\circ} \mathrm{C}$ or $-80{ }^{\circ} \mathrm{C}$ for 5 months, and monitored by SRM mass spectrometry.

Glucagon $_{1-29}$ degradation was observed across all of the stress conditions investigated, except for the aprotinin stabilised samples frozen for 1 month (Table 3). Apart from these samples the use of aprotinin had a negligible effect, for example after 6 hours 20 minutes at room temperature, glucagon ${ }_{1-29}$ in unstabilised samples had degraded to $58.3 \%$ of their $0 \mathrm{hr}$ level, whereas in aprotinin stabilised samples it had degraded to $60.7 \%$. Whilst aprotinin's lack of stabilisation ability has been reported previously ${ }^{[14]}$ this study used C-terminal directed antibodies and antibodies directed against the 6-15 region of glucagon, and therefore was not able to assess the impact of aprotinin in preventing N-terminal degradations. In contrast, our LC/MS assay assessed degradation across the entire molecule, thereby assessing whether aprotinin has a stabilising effect across the whole molecule. It appears that aprotinin only has a minimal stabilising effect, which requires slow metabolism kinetics, such as those experienced in frozen samples, to be observed.

As expected lowering the temperature reduced glucagon degradation. For example after 6 hours 20 minutes at $4^{\circ} \mathrm{C}$ glucagon had degraded to approximately $86 \%$ of 0 hour levels; this corroborates our previous observations ${ }^{[23]}$. Conversely increasing the storage time increased degradation. For example, after 26 hours 20 minutes at room temperature glucagon had degraded to approximately $11 \%$ of $0 \mathrm{hr}$ levels. Subjecting samples to 4 freeze-thaw cycles (cycling at $-80{ }^{\circ} \mathrm{C} /+4{ }^{\circ} \mathrm{C}$, or $-20{ }^{\circ} \mathrm{C} /+4{ }^{\circ} \mathrm{C}$ ) led to degradation to approximately $84 \%$ of 0 hour levels, with no significant difference between the different storage temperatures. The 
total amount of time these samples spent at $4{ }^{\circ} \mathrm{C}$ before extraction was 4 hours 10 minutes, even though the degradation is similar to non-freeze-thaw samples left at 6 hour 20 minutes $4^{\circ} \mathrm{C}$, suggesting the process of freeze-thawing may lead to additional degradation, which is again consistent to that observed previously ${ }^{[23]}$.

Glucagon $_{3-29}$ was the most intense metabolite for samples with relatively low levels of glucagon degradation, for example those stored at $6 \mathrm{hr} 20 \mathrm{mins}$ at $4{ }^{\circ} \mathrm{C}$, freeze thaw samples, and frozen samples. This is in agreement with the time course studies above, which showed that Glucagon $3-29$ levels peak, before further metabolism into $[\mathrm{pGlu}]^{3}$ glucagon $_{3-29}$. Despite being the most intense metabolite the response was fairly low, for example the 6 hours 20 minutes at $4^{\circ} \mathrm{C}$ samples gave glucagon ${ }_{3-29}$ responses of approximately $6 \%$ their 0 hour glucagon $_{1-29}$ response. However as explained above the responses do not necessary correlate with abundances. The formation of such metabolites would lead to inaccurate quantitation if C-terminal directed antibodies were used as the basis of an immunoassay quantitation method. In fact, all of the metabolites detected have intact C-terminals so all have the potential to cross react with such antibodies.

Samples stored at $-80{ }^{\circ} \mathrm{C}$ showed less glucagon degradation than those $-20{ }^{\circ} \mathrm{C}$ (Table 3 ) and correspondingly metabolite formation was greater at $-20{ }^{\circ} \mathrm{C}$ than $-80{ }^{\circ} \mathrm{C}$ (Figure 8). Interestingly oxidised $[\mathrm{pGlu}]^{3}$ glucagon $_{3-29}$ was not observed in samples stored at $-80{ }^{\circ} \mathrm{C}$, this is despite similar levels of $\left[\mathrm{pGlu}^{3}\right.$ glucagon $_{3-29}$ being present as in $-20{ }^{\circ} \mathrm{C}$ samples.

\section{Metabolites formed in Physiological Study Samples}

Plasma samples $(n=87)$ from a physiological Study involving the infusion of glucagon were extracted using the sensitive 2D method before analysis with SRM. The samples were analysed in two sets with the second set was assayed two months after the first. The extracts were also analysed using our glucagon quantitation method ${ }^{[23]}$ and found to contain a maximum of $1.3 \mathrm{ng} / \mathrm{mL}$ of glucagon, which is 7,692 fold less than the $10 \mu \mathrm{g} / \mathrm{mL}$ samples used for the experiments described above. Therefore due to the low levels, we were not anticipating being able to observe all of the metabolites.

Despite the low glucagon $_{1-29}$ concentrations, glucagon gl-29 $_{3}$ was detected in the majority of samples $(78 \%)$ and was found to approximately track glucagon ${ }_{1-29}$ levels (Figure 9 a-d). The 
first set of samples $(n=25)$ gave mean glucagon ${ }_{3-29}$ levels of $14.3 \%(C V=33.4)$ of glucagon gl-29 $_{1}$ levels (Figure 9 a,c,d), whilst the second set $(n=62)$ gave mean glucagon ${ }_{3-29}$ levels of $9.0 \%$ $(\mathrm{CV}=28.1)$ (Figure $9 \mathrm{~b}) .[\mathrm{pGlu}]^{3}$ glucagon $_{3-29}$ was detected in $10 \%(\mathrm{n}=9)$ of the samples, all of which were from one subject (volunteer 3) and was analysed as part of the first set of samples (Figure $9 \mathrm{c}$-d). The levels were approximately half of glucagon ${ }_{3-29}$ levels (mean= $48.3 \%, \mathrm{CV}=12.9 \%, 2$ outliers excluded). The low levels of glucagon likely prevented this metabolite, and others, from being detected in other samples. If glucagon is measured by immunoassays techniques that do not require an intact $\mathrm{N}$ terminus ${ }^{[14]}$ then these metabolites could cause glucagon levels to be overestimated.

Freshly prepared QC samples were extracted alongside the clinical samples, and did not contain detectable metabolites, thereby demonstrating that those observed were not an artefact of the extraction procedure. However clinical samples were stored at $-20{ }^{\circ} \mathrm{C}$ before analysis, and as described previously metabolites were formed in spiked samples stored under these conditions. Specifically, after 5 months storage glucagon ${ }_{3-29}$ was detected at $3.3 \%$ of glucagon $_{1-29}$ levels $(\mathrm{CV}=8.7 \%)$ whilst $[\mathrm{pGlu}]^{3}$ glucagon $_{3-29}$ was detected at $23.1 \%$ of glucagon $_{3-29}$ levels $(\mathrm{CV}=11.9)$; these values were lower at $2.8 \%(\mathrm{CV}=3.6 \%)$ and $11.8 \%$ $(\mathrm{CV}=15.1 \%)$ after 1 month storage. However, as clinical samples were analysed within 5 months and their mean detected glucagon ${ }_{3-29}$ levels are up to 4.3 fold greater, and mean $[\mathrm{pGlu}]^{3}$ glucagon $_{3-29}$ levels are 2.1 fold greater, than those observed in the spiked samples this suggests that at least some metabolism occurs in vivo. 

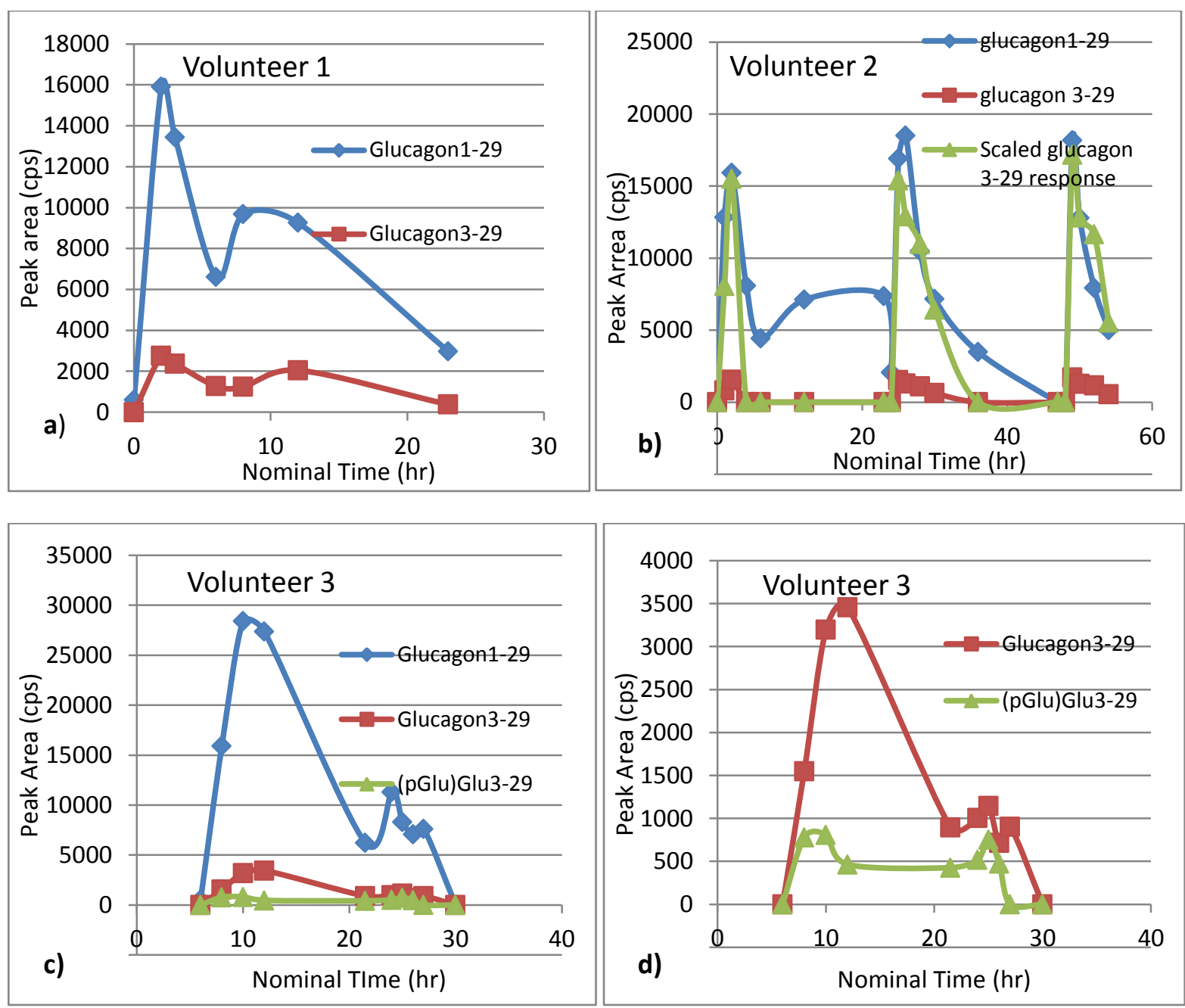

Figure 9 Glucagon metabolites detected in clinical samples.

a) Glucagon ${ }_{1-29}$ and glucagon ${ }_{\text {3-29. }}$.

b) Glucagon ${ }_{1-29}$, glucagon gl-29 $_{3}$ and Glucagon ${ }_{3-29}$ scaled by a factor of 10 to emphasise the relationship between the metabolite and parent levels. c) Glucagon ${ }_{1-29}$, Glucagon $_{3-29}$, and [pGlu] $]^{3}$ glucagon $_{3-29}$.

d) Glucagon 3-29, and [pGlu] $]^{3}$ glucagon 3-29only. 


\section{CONCLUSION}

Metabolites formed from the incubation of glucagon $_{1-29}$ in human plasma have been identified using high resolution mass spectrometry. The presence of the previously reported $20 \%$ serum (buffer) metabolite pyroglutamyl [pGlu $]^{3}$ glucagon $_{3-29}$ was confirmed, however we also detected significant amounts of glucagon ${ }_{3-29}$ which has not been reported in buffered serum. In fact, at low levels of glucagon metabolism this was the major metabolite. Glucagon $_{19-29}$, or miniglucagon, was also identified in plasma, which has previously only been observed in liver plasma membranes ${ }^{[6]}$ or pancreatic cells ${ }^{[7]}$. We also identified the novel metabolites glucagon $20-29$ and glucagon $21-29$. Further studies are needed to determine whether these, like minglucagon, have an important function in vivo. Additionally we identified two oxidised forms of $[\mathrm{pGlu}]^{3}$ glucagon $_{3-29}$. All of the metabolites identified contain an intact $\mathrm{C}$-terminal and have the potential to cross react with antibodies in glucagon $_{1-29}$ immunoassays that are directed again this portion of the molecule $^{[14]}$. This could lead to lead to inaccurate glucagon ${ }_{1-29}$ quantitation and consequently clinical decisions could be made on the basis of inaccurate data.

Metabolite formation was investigated under various stress conditions, representative of typical laboratory sample handling conditions. Aprotinin stabilisation was found to have negligible effect demonstrating more effective stabilisation approaches should be developed.

Despite the low levels of glucagon present in the clinical samples the glucagon s-29 $_{\text {metabolite }}$ was detected in the majority of them, and was the major metabolite, whilst $\left[\mathrm{pGlu}^{3}\right.$ glucagon $_{3-29}$ was detected in just one subject. However, at least some of the metabolites observed are likely to be formed as a result of in vitro plasma protease metabolism that occurs during sample storage rather than being formed in vivo, again emphasising the need for alternative stabilisation approaches. Once these are developed, the in vivo formation of the novel metabolites detailed in this paper can be accurately assessed within clinical samples. 


\section{REFERENCES}

[1] A. Kolb, S. Rieder, D. Born, N. A. Giese, T. Giese, G. Rudofsky, J. Werner, M. W. Büchler, H. Friess, I. Esposito, J. Kleeff. Glucagon/insulin ratio as a potential biomarker for pancreatic cancer in patients with new-onset diabetes mellitus. Cancer Biol. Ther. 2009, 8, 1527.

[2] F. P. Alford, S. R. Bloom, J. D. Nabarro. Glucagon metabolism in man, studies on the metabolic clearance rate and the plasma acute disappearance time of glucagon in normal and diabetic subjects. J Clin Endocrinol Metab 1976, 42, 830.

[3] F. Authier, B. Desbuquois. Glucagon receptors. Cell. Mol. Life Sci. 2008, 65, 1880.

[4] M. J. Sheetz, H. S. Tager. Characterization of a glucagon receptor-linked protease from canine hepatic plasma membranes. Partial purification, kinetic analysis, and determination of sites for hormone processing. J. Biol. Chem. 1988, 263, 19210.

[5] W. A. Hagopian, H. S. Tager. Hepatic glucagon metabolism. Correlation of hormone processing by isolated canine hepatocytes with glucagon metabolism in man and in the dog. J. Clin. Invest. 1987, 79, 409.

[6] P. Blache, A. Kervran, D. Le-Nguyen, M. Dufour, A. Cohen-Solal, W. Duckworth, D. Bataille. Endopeptidase from rat liver membranes, which generates miniglucagon from glucagon. J. Biol. Chem. 1993, 268, 21748.

[7] G. Fontés, A.-D. Lajoix, F. Bergeron, S. Cadel, A. Prat, T. Foulon, R. Gross, S. Dalle, D. Le-Nguyen, F. Tribillac, D. Bataille. Miniglucagon (MG)-generating endopeptidase, which processes glucagon into $\mathrm{MG}$, is composed of $\mathrm{N}$-arginine dibasic convertase and aminopeptidase B. Endocrinology 2005, 146, 702.

[8] D. Bataille, G. Fontés, S. Costes, C. Longuet, S. Dalle. The glucagon-miniglucagon interplay: a new level in the metabolic regulation. Ann. N. Y. Acad. Sci. 2006, 1070, 161.

[9] D. R. Peterson, E. A. Green, S. Oparil, J. T. Hjelle. Transport and hydrolysis of glucagon in the proximal nephron. Am. J. Physiol. - Ren. Physiol. 1986, 251, F460.

[10] J. A. Pospisilik, S. A. Hinke, R. A. Pederson, T. Hoffmann, F. Rosche, D. Schlenzig, K. Glund, U. Heiser, C. H. McIntosh, H. Demuth. Metabolism of glucagon by dipeptidyl peptidase IV (CD26). Regul. Pept. 2001, 96, 133.

[11] R. Mentlein. Dipeptidyl-peptidase IV (CD26)-role in the inactivation of regulatory peptides. Regul. Pept. 1999, 85, 9.

[12] V. J. Hruby. Structure-conformation-activity studies of glucagon and semi-synthetic glucagon analogs. Mol. Cell. Biochem. 1982, 44, 49.

[13] S. A. Hinke, J. A. Pospisilik, H. U. Demuth, S. Mannhart, K. Kühn-Wache, T. Hoffmann, E. Nishimura, R. A. Pederson, C. H. McIntosh. Dipeptidyl peptidase IV 
(DPIV/CD26) degradation of glucagon. Characterization of glucagon degradation products and DPIV-resistant analogs. J. Biol. Chem. 2000, 275, 3827.

[14] M. J. Bak, N. W. Albrechtsen, B. Hartmann, J. Pedersen, M. Christensen, T. Vilsboll, F. Knop, C. F. Deacon, L. O. Dragsted, J. J. Holst. No Effect of Aprotinin (Trasylol $\mathrm{TM}$ ) on Degradation of Exogenous and Endogenous Glucagon in Human , Mouse and Rat Plasma. J. Endocrinol. Diabetes 2014, 29, 1.

[15] J. Mess, R. Lavallee, D. Villeneuve, F. Garofolo, Challenges Associated with the Bioanalytical Method Development of the Glucagon by LC-MS in a Regulated Environment, in American Association of Pharmaceutical Scientists ConferenceSan Diego, CA, May 21-23, 2012.

[16] BD ${ }^{\mathrm{TM}}$ P800 Blood Collection System Enabling Metabolic Biomarker Preservation P800 Preserves Metabolic Peptides. Becton, Dickinson Company, Franklin Lakes, NJ, USA 2009.

[17] J. H. Sloan, R. W. Siegel, Y. T. Ivanova-Cox, D. E. Watson, M. A. Deeg, R. J. Konrad. A novel high-sensitivity electrochemiluminescence (ECL) sandwich immunoassay for the specific quantitative measurement of plasma glucagon. Clin. Biochem. 2012, 45, 1640.

[18] F. P. Alford, S. R. Bloom, J. D. Nabarro. Glucagon levels in normal and diabetic subjects: Use of a specific immunoabsorbent for glucagon radioimmunoassay. Diabetologia 1977, 13, 1.

[19] M. J. Bak, N. W. Albrechtsen, J. Pedersen, B. Hartmann, M. Christensen, T. Vilsbøll, F. K. Knop, C. F. Deacon, L. O. Dragsted, J. J. Holst. Specificity and sensitivity of commercially available assays for glucagon and oxyntomodulin measurement in humans. Eur J Endocrino 2014, 170, 529.

[20] N. J. Wewer Albrechtsen, B. Hartmann, S. Veedfald, J. a Windeløv, A. Plamboeck, K. N. Bojsen-Møller, T. Idorn, B. Feldt-Rasmussen, F. K. Knop, T. Vilsbøll, S. Madsbad, C. F. Deacon, J. J. Holst. Hyperglucagonaemia analysed by glucagon sandwich ELISA: nonspecific interference or truly elevated levels? Diabetologia 2014, 57, 1919.

[21] R. Trebbien, L. Klarskov, M. Olesen, J. J. Holst, R. D. Carr, C. F. Deacon. Neutral endopeptidase 24.11 is important for the degradation of both endogenous and exogenous glucagon in anesthetized pigs. Am J Physiol Endocrinol Metab 2004, 3, 431 .

[22] F. Garofolo, J. N. Mess, L. P. Morin, M. Aiello, X. Misonne, G. Impey, J. Cardenas, J. Michon, Glucagon bioanalysis by LC-MS: unprecedented level of sensitivity (10 $\mathrm{pg} / \mathrm{ml}$ ) for a novel formulation, in 2013 American Association of Pharmaceutical Scientists National Biotechnology ConferenceSan Diego, CA, 20-22 May, 2013.

[23] J. W. Howard, R. G. Kay, T. Tan, J. Minnion, M. Ghatei, S. Bloom, C. S. Creaser. Development of a high throughput UHPLC-MS/MS (SRM) method for the quantitation of endogenous glucagon from human plasma (accepted, in press). Bioanalysis 2014, TBC, TBC. 
[24] D. C. Delinsky, K. T. Hill, C. A. White, M. G. Bartlett. Quantitation of the large polypeptide glucagon by protein precipitation and LC/MS. Biomed. Chromatogr. 2004, 18, 700 .

[25] Y. X. Li, M. Hackman, C. Y. Wang. Quantitation of polypeptides (glucagon and salmon calcitonin) in plasma samples by "high resolution" on a triple quadrupole mass spectrometer. Bioanalysis 2012, 4, 685.

[26] V. Lapko, P. Brown, R. Nachi, C. Kafonek, A. Dzerk, B. Retke, C. Ohnmacht, C. Sheldon, I. Davis, Exploring quantification of peptides: measurement of glucagon in human plasma by LC-MS/MS, in EBF 3rd Annual Open Symposium: From Challenges to SolutionsBarcelona, Spain, 1 - 3 December, 2010.

[27] WMA Declaration of Helsinki - Ethical Principles for Medical Research Involving Human Subjects. WMA Gen. Assem. Helsinki, Finland, 1964.

[28] S. Schilling, T. Hoffmann, S. Manhart, M. Hoffmann, H.-U. Demuth. Glutaminyl cyclases unfold glutamyl cyclase activity under mild acid conditions. FEBS Lett. 2004, $563,191$.

[29] M. Holčapek, R. Jirásko, M. Lísa. Recent developments in liquid chromatographymass spectrometry and related techniques. J. Chromatogr. A 2012, 1259, 3.

[30] D. S. Rehder, C. R. Borges. Cysteine sulfenic acid as an intermediate in disulfide bond formation and non-enzymatic protein folding. Mol. Biomarkers 2011, 49, 7748.

[31] X. Liang, A. Kaya, Y. Zhang, D. T. Le, D. Hua, V. N. Gladyshev. Characterization of methionine oxidation and methionine sulfoxide reduction using methionine-rich cysteine-free proteins. BMC Biochem. 2012, 13, 21.

[32] H. K. Khor, M. E. Jacoby, T. C. Squier, G. C. Chu, D. Chelius. Identification of methionine sulfoxide diastereomers in immunoglobulin gamma antibodies using methionine sulfoxide reductase enzymes. MAbs 2010, 2, 299.

[33] F. Authier, B. I. Posner, J. J. Bergeron. Insulin-degrading enzyme. Clin Invest Med 1996, 19, 149.

[34] K. Rose, L. A. Savoy, A. V Muir, J. G. Davies, R. E. Offord, G. Turcatti. Insulin proteinase liberates from glucagon a fragment known to have enhanced activity against $\mathrm{Ca} 2++\mathrm{Mg} 2+-$ dependent ATPase. Biochem. J. 1988, 256, 847.

[35] V. S. Sharov, D. A. Ferrington, T. C. Squier, C. Schöneich. Diastereoselective reduction of protein-bound methionine sulfoxide by methionine sulfoxide reductase. FEBS Lett. 1999, 247. 


\section{TABLES}

Table 1 Potential metabolites formed by glucagon in human plasma identified using LRMS

\begin{tabular}{|c|c|c|c|c|c|c|}
\hline Peak & $\begin{array}{l}\text { Observed } \\
(\mathrm{m} / \mathrm{z})\end{array}$ & $\begin{array}{l}\text { Putative } \\
\text { Charge } \\
\text { state }\end{array}$ & $\begin{array}{l}\text { Putative } \\
\text { mass } \\
\text { (Da) }\end{array}$ & Putative ID & $\begin{array}{l}\text { Average } \\
\text { Theoretical } \\
\text { Mass (Da) }\end{array}$ & $\begin{array}{l}\text { Mass } \\
\text { Accuracy } \\
(\mathrm{ppm})\end{array}$ \\
\hline 1 & 697.5 & 5 & 3482.5 & \multirow{2}{*}{ glucagon $_{1-29}$} & \multirow{2}{*}{$3482.7473^{1}$} & -82 \\
\hline 1 & 871.5 & 4 & 3482.0 & & & -224 \\
\hline $2 a$ & 815.1 & 4 & 3256.4 & \multirow{2}{*}{ glucagon $_{3-29}(?)$} & \multirow{2}{*}{$3258.53072^{1}$} & -663 \\
\hline $2 a$ & 1086.5 & 3 & 3256.5 & & & -630 \\
\hline $2 b$ & 8153 & 4 & 3257.2 & \multirow{2}{*}{ glucagon $_{3-29}(?)$} & \multirow{2}{*}{$3258.53072^{1}$} & -418 \\
\hline $2 b$ & 1086.4 & 3 & 3256.2 & & & $\begin{array}{l}-410 \\
-722\end{array}$ \\
\hline $2 c$ & 815.1 & 4 & 3256.4 & \multirow{2}{*}{ glucagon $_{3-29}(?)$} & \multirow{2}{*}{$3258.53072^{1}$} & -663 \\
\hline & 1087.4 & 3 & 3259.2 & & & 198 \\
\hline 3 & 577.3 & 2 & 1152.6 & glucagon 2120 & $1153.30694^{1}$ & -627 \\
\hline 4 & 641.3 & 2 & 1280.6 & glucagon $20-20$ & $1281.43616^{1}$ & -665 \\
\hline 5 & 6768 & 2 & 13516 & (1) & $135251406^{1}$ & 687 \\
\hline & & & & 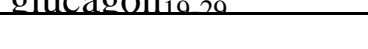 & & \\
\hline & 8111 & 4 & 3240.4 & \multirow{2}{*}[\mathrm{pGlu}]{$^{3}$ glucagon $_{3-29}$} & \multirow{2}{*}{$3241.5002^{2}$} & -349 \\
\hline 6 & 1081.2 & 3 & 3240.6 & & & -285 \\
\hline
\end{tabular}

1 Theoretical average mass value calculated from peptide sequence using

http://proteomicsresource.washington.edu/cgi-bin/fragment.cgi

2 Calculated by subtracting $\mathrm{NH}_{3}$ average molecular mass from glucagon ${ }_{3-29}$ mass. 
Table 2 Glucagon metabolites in human plasma confirmed using HRMS

\begin{tabular}{|c|c|c|c|c|c|}
\hline Peak & $\begin{array}{l}\text { Observed } \\
(\mathrm{m} / \mathrm{z})\end{array}$ & $\begin{array}{l}\text { Charge } \\
\text { state }\end{array}$ & Metabolite ID & $\begin{array}{l}\text { Theoretical } \\
(\mathrm{m} / \mathrm{z})\end{array}$ & $\begin{array}{l}\text { Mass Accuracy } \\
(\mathrm{ppm})\end{array}$ \\
\hline 1 & 697.12921 & 5 & \multirow[t]{2}{*}{ glucagon $_{1-29}$} & $697.13042^{1}$ & -1.7 \\
\hline 1 & 871.15967 & 4 & & $871.16120^{1}$ & -1.8 \\
\hline $2 a$ & 814.87933 & 4 & \multirow{2}{*}{${\text { oxidised }[\mathrm{pGlu}]^{3} \text { glucagon }}_{3-29}$} & $814.88056^{2}$ & -1.5 \\
\hline $2 a$ & 1086.17004 & 3 & & $1086.17165^{2}$ & -1.5 \\
\hline & & & \multirow{3}{*}{${\text { oxidised [pGlu] }{ }^{3} \text { glucagon }}_{3-29}$} & & \\
\hline $2 b$ & 814.87933 & 4 & & $814.88056^{2}$ & -1.5 \\
\hline $2 b$ & 1086.17029 & 3 & & $1086.17165^{2}$ & -1.3 \\
\hline $2 c$ & 81513751 & 4 & \multirow{2}{*}{ gluc } & $81513847^{1}$ & -12 \\
\hline $2 c$ & 1086.51331 & 3 & & 108651553 & -20 \\
\hline & & & \multirow{3}{*}{$g$} & & \\
\hline 3 & 577.26898 & 2 & & $577.27097^{1}$ & -3.4 \\
\hline 3 & 1153.53027 & 1 & & $1153.53466^{1}$ & -3.8 \\
\hline 4 & 641.29828 & 2 & \multirow{2}{*}{ gluca } & $64130026^{1}$ & -31 \\
\hline 4 & 1281.58899 & 1 & & 1281.59324 & -3.3 \\
\hline & & & & & \\
\hline 5 & 676.81628 & 2 & \multirow{2}{*}{ glu } & $676.81881^{1}$ & -3.7 \\
\hline 5 & 1352.62651 & 1 & & $1352.63035^{1}$ & -2.8 \\
\hline 6 & 810.87982 & 4 & \multirow{2}{*}{ 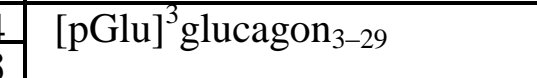 } & $810.88183^{2}$ & -2.5 \\
\hline 6 & 10 & 3 & & $201^{2}$ & -2.4 \\
\hline
\end{tabular}

1 Theoretical monoisopic value calculated from peptide sequence using http://proteomicsresource.washington.edu/cgi-bin/fragment.cgi

2 Values calculating from other masses in table by the masses of modifications in http://www.weddslist.com/ms/tables.html

Table 3 Glucagon degradation after 1 month and 5 months in a freezer

\begin{tabular}{|l|l|r|}
\hline \multirow{2}{*}{$\begin{array}{c}\text { Sample } \\
\text { (stabiliser/ storage conditions) }\end{array}$} & \multicolumn{2}{c|}{ \% stability } \\
\cline { 2 - 3 } & $\begin{array}{l}\text { Month } \\
\text { Aprotinin stabilised }\left(-20^{\circ} \mathrm{C}\right)\end{array}$ & \multicolumn{1}{l|}{ Months } \\
\hline Unstabilised $\left(-20^{\circ} \mathrm{C}\right)$ & 88.1 & 86.6 \\
\hline Aprotinin stabilised $\left(-80^{\circ} \mathrm{C}\right)$ & 98.8 & 85.5 \\
\hline Unstabilised $\left(-80^{\circ} \mathrm{C}\right)$ & 89.6 & 91.6 \\
\hline
\end{tabular}

